\title{
Erratum
}

\section{Evidence of Reduced CBG Cleavage in Abdominal Obesity: A Potential Factor in Development of the Metabolic Syndrome}

M. A. Nenke, J. G. Lewis, W. Rankin, D. J Torpy

Horm Metab Res 2016; 48 (08): 523-528

DOI: $10.1055 / \mathrm{s}-0042-108728$

Fig. 1 was published incorrectly in the print issue. Please see the correct version below.

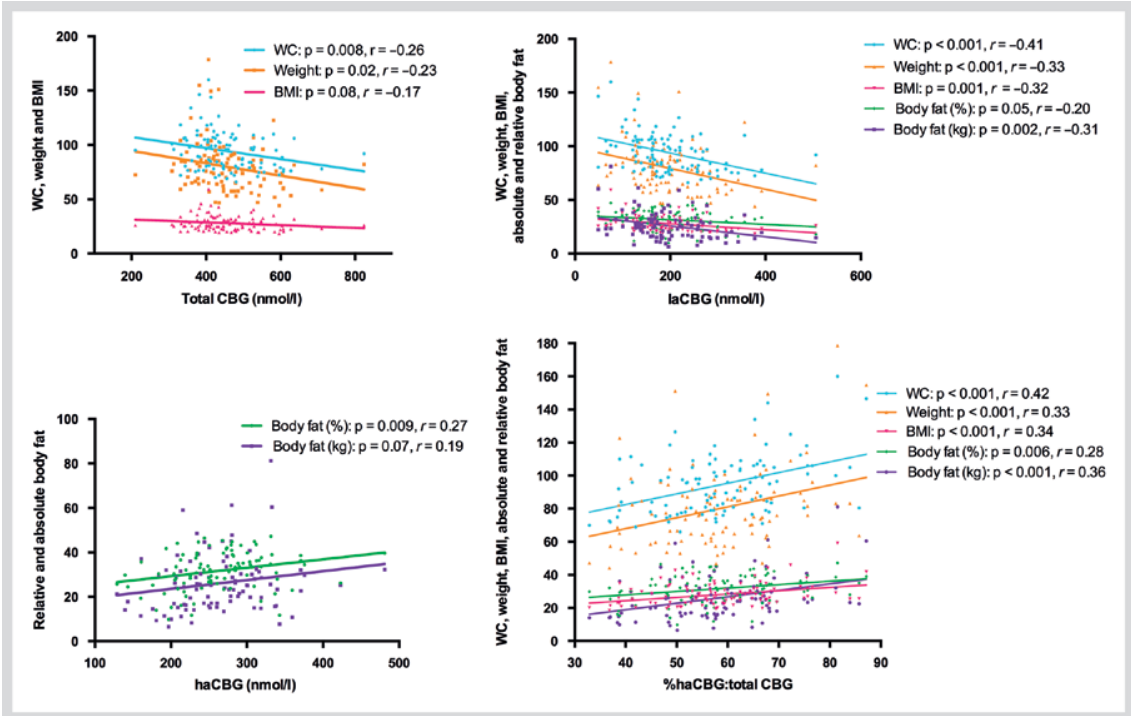

Fig. 1 Correlations between CBG affinity forms and anthropometric measurements in the total cohort. WC: Waist circumference $(\mathrm{cm})$; weight $(\mathrm{kg})$; BMI:Body mass index $\left(\mathrm{kg} / \mathrm{m}^{2}\right)$. 